Discussion This study described the QWL of cancer survivors and associations between QWL and health- and work-related variables. Based on these variables it is possible to indicate groups of cancer survivors who need more attention and support regarding QWL and work continuation.

\section{TOWARDS LEAN, SIX-SIGMA, AND LEAN SIX SIGMA OHS IMPACTS IN UNIVERSITIES}

S Nadeau. École de technologie supérieure, Montreal, Canada

10.1136/oemed-2018-ICOHabstracts. 1632

Introduction Our universities must adapt to increasingly uncertain environments, face fierce international competition, manage budget cuts, increased auditing, rapid technological changes and increasing expectations of various increasingly demanding social partners, and even personalise their academic programs. The 2000s brought interest in lean, six-sigma, and lean six sigma methods. This review of the literature summarises and analyses the documented experience of public and private universities around the world with these approaches.

Methods Scientific databases were queried to retrieve the relevant literature published from 2000 to 2016. The search was completed using the snowball effect. The results were sorted by geographical region, type of process and decisional level. The challenges addressed were also listed and sorted.

Result These approaches are innovative in the university setting. While few results are documented, experiments at American, British, Mexican, Finnish, South African, Indian and Saudi institutions are all on record. Activities in support of teaching and university community services were the principal targets. A single research-related case was retrieved, which dealt with supporting activities.

Discussion Lean, six sigma and lean six sigma methods are not deployed in any systematic way. The principal obstacles are system complexity and the difficulties of adapting the tools to institutional reality and of defining and applying the concepts of client and added value. The few documented measured results are isolated and do not support any generalisation. Impact studies are limited primarily to qualitative statements describing challenges and factors associated with success. No study of the impact of these approaches on the occupational health and safety of university staff was retrieved. Since the lean manufacturing literature mentions frequently both positive (task enrichment, autonomy) and negative (musculoskeletal injuries, stress, fatigue, professional burn-out and others) impacts, it cannot be ruled out that such impacts might be noted also in the university setting.

\section{MANAGEMENT OF STRESS IN THE WORKPLACE: A NATIONAL RESPONSE TO IMPLEMENTING STRESS MANAGEMENT INTERVENTIONS}

${ }^{1}$ Emer Carroll*, ${ }^{2}$ Nodlaig Carroll. ${ }^{1}$ National Health and Safety Function (NHSF), Health Service Executive (HSE), Ireland; ${ }^{2}$ Organisational Psychology Unit, Health Service Executive (HSE), Ireland

\subsection{6/oemed-2018-ICOHabstracts. 1633}

Introduction In 2012, the HSE launched the national 'Policy on Prevention and Management of Stress in the Workplace' which was developed by a cross-sectorial multi-disciplinary group. In line this policy, the Organisational Psychology Unit, local HR (HSE West/North West/Mid West) and National HR designed resources and risk assessment tools to enable managers address workplace stress.

The 2015 European Safety Campaign 'Healthy Workplaces Manage Stress' afforded the HSE an opportunity to develop a national response to workplace stress as a psychosocial risk. The National Health and Safety Function (NHSF) recognised the need for a collaborative response and facilitated the development of a Workplace Stress Working Group (WSG). The WSG compiled of professionals from Organisational Psychology, Health and Safety, Occupational Health $(\mathrm{OH})$, Employee Assistance and Counselling Services (EASC), Learning, Education and Development (LED), Health Promotion (HP and I) and HR.

Methods The WSG developed the HSE's Cycle of Stress Management (Identification, Prevention, Support and Assistance and Monitoring and Review) and created supporting information material.

A seminar programme was developed to:

- provide support and disseminate tools to managers,

- implement workplace stress risk assessment,

- promote manager leadership in pro-actively managing and supporting staff health and wellbeing,

- assess personal health behaviours and

- create supportive positive work environments.

Key stakeholders from the WSG co-presented at these seminars.

Result To date, nineteen accredited seminars were held, with 842 attendees. $95 \%$ of evaluations received $(75 \%$ response rate) were hugely positive.

Data from the NHSF, demonstrated one hospital increased its use of the stress management risk assessment tool by $62.5 \%$, following two stress management seminars.

Discussion Anecdotal evidence suggests that managers are more confident in pro-actively addressing workplace stress and this is evident with the recent results of Health Sector Staff Survey Your Opinion Counts showing that almost 70\% of staff are aware of the facilities to support stress in work.

\section{STRESS, BURNOUT, PSYCHOSOMATIC SYMPTOMS AND THEIR ASSOCIATION WITH WORKING CONDITIONS IN DOCTORS OF HOSPITALS IN MEXICO CITY}

ME Palacios-Nava*, MP Román-Paz. Faculty of Medicine, National Autonomous University of Mexico, Mexico City, Mexico

10.1136/oemed-2018-ICOHabstracts. 1634

Introduction The Burnout syndrome occurs frequently in health care workers. It is associated with stressors present in the medical work. These conditions are different between residents and doctors attached. The objective of this study was to identify the association between working conditions, stress burnout and psychosomatic symptoms in hospital physicians in Mexico.

Methods A cross-sectional study was carried out on a sample of 724 physicians in seven hospitals from Mexico City. An instrument was applied to determine socio-demographic characteristics and working conditions. To evaluate stress, burnout and psychosomatic manifestations, Wolfgang, Maslach and Kroenke inventories were used. They had a reliability of 0.91 , 0.83 and 0.78 respectively 